Научная статья

УДК 343.1

DOI: $10.17150 / 2411-6122.2021 .3 .42-50$

Обеспечение в уголовном процессе права на защиту при помещении лица в медицинскую организацию, оказывающую психиатрическую помощь в стационарных условиях

\author{
А.В. Шатрова \\ Российский государственный университет правосудия, г. Москва, Российская Федерация, \\ anna9135891004@gmail.com
}

Аннотация. Вовлечение в уголовное судопроизводство лиц с психическими расстройствами требует дополнительных процессуальных гарантий обеспечения их прав. В российском уголовном судопроизводстве процессуальный статус лица, в отношении которого ведется производство о применении принудительных мер медицинского характера, является недостаточно определенным. Такая нормативная конструкция затрудняет реализацию таким лицом права на защиту. В данной статье рассматриваются отдельные проблемы обеспечения права на защиту при решении вопроса о помещении душевнобольного лица в психиатрический стационар. Основываясь на системном анализе действующих уголовно-процессуальных норм и международно-правовых стандартов обеспечения справедливого судебного разбирательства по исследуемой категории уголовных дел, автор формулирует предложения по совершенствованию уголовно-процессуального закона и практики его применения. Предлагается на нормативном уровне закрепить особую меру процессуального принуждения, состоящую в принудительном помещении лица в психиатрический стационар.

Ключевые слова: уголовное судопроизводство, психиатрический стационар, психическое расстройство, принудительные меры медицинского характера, право на защиту.

Для цитирования: Шатрова А.В. Обеспечение в уголовном процессе права на защиту при помещении лица в медицинскую организацию, оказывающую психиатрическую помощь в стационарных условиях / А.В. Шатрова. - DOI: 10.17150/2411-6122.2021.3.42-50 // Сибирские уголовно-процессуальные и криминалистические чтения. - 2021. - № 3. - С. 42-50.

Original article

\title{
Ensuring the Right of a Person Placed in a Psychiatric Care Hospital to Defense in Criminal Proceedings
}

\author{
A.V. Shatrova \\ Russian State University of Justice, Moscow, the Russian Federation, \\ anna9135891004@gmail.com
}

\begin{abstract}
The involvement of persons suffering from mental disorders into criminal court proceedings requires additional procedural guarantees of ensuring their rights. The procedural status of a person involved in proceedings regarding the application of compulsory medical treatment is not sufficiently well-defined in Russian criminal procedure. Such a normative construct makes it harder for this
\end{abstract}


person to exercise their right to defense. The author examines some problems of ensuring a right to defense when making a decision on placing a mentally ill person in a psychiatric care facility. Based on a systemic analysis of current criminal procedure norms and international law standards of ensuring a just and fair court hearing in the category of criminal cases under consideration, the author presents ideas on improving the criminal procedure law and the practice of its enforcement. It is suggested that a special norm of procedural compulsion consisting in the forceful placement of a person in a psychiatric care hospital should be incorporated in law.

Keywords: criminal proceedings, psychiatric hospital, mental disorder, compulsory medical measures, a right to defense.

For citation: Shatrova A.V. Ensuring the Right of a Person Placed in a Psychiatric Care Hospital to Defense in Criminal Proceedings. Sibirskie Ugolovno-Processual'nye $i$ Kriminalisticheskie Chteniya $=$ Siberian Criminal Procedure and Criminalistic Readings, 2021, no 3, pp. 42-50. DOI: 10.17150/24116122.2021.3.42-50.(In Russian).

Особенности психического состояния лица, совершившего преступление или уголовно-наказуемое деяние, могут стать основанием для дифференциации производства по уголовному делу по субъектному признаку и потребовать дополнительных гарантий обеспечения его прав. Исследователи данной проблематики, со ссылками на данные Bceмирной организации здравоохранения, фиксируют тенденцию к увеличению числа лиц с теми или иными психическими расстройствами [1]. Специфика процессуальной деятельности при расследовании и рассмотрении таких дел в значительной мере связана с наличием потенциальных трудностей в реализации лицами с психическими расстройствами их процессуальных прав. Значительная вариативность картины психического заболевания, нелинейность его развития и разрешения могут стать препятствиями и в осуществлении права на защиту.

В уголовно-процессуальном праве право на защиту рассматривается как фундаментальное право, принадлежащее уголовно преследуемому лицу, и направленное на законное противостояние выдвинутому против него в той или иной форме обвинению. В основе данного процессуального права подозрева- емого, обвиняемого, подсудимого лежат базовые стандарты прав человека, получившие закрепление в нормах международного и конституционного права. Следует согласиться с Н.Н. Неретиным в том, что «сам принцип обеспечения обвиняемому права на защиту пронизывает все уголовное судопроизводство. При расследовании преступлений обвиняемый, в соответствии со ст. 47 УПК, пользуется предоставленными ему правами. Нормы УПК не только провозглашают право обвиняемого на защиту, но и требует от лиц, осуществляющих уголовное преследование, обеспечить обвиняемому возможность пользоваться своими правами» [2, с. 93].

Однако лицо, в отношении которого ведется производство о применении принудительных мер медицинского характера, может быть отнесено к категории уголовно преследуемых лиц с определенными оговорками, поскольку может быть освобождено от уголовной ответственности по причинам, чаще всего не зависящим ни от воли самого лица, ни от действий должностных лиц органов, осуществляющих его уголовное преследование. Этим же и определяется специфика процессуального положения лица, в отношении которого ведется производство о применении принуди- 
тельных мер медицинского характера. Российский законодатель выделяет его как отдельного, специального участника уголовного судопроизводства, что вытекает из системного толкования норм, закрепленных в гл. 51 Уголовно-процессуального кодекса Российской Федерации (далее - УПК РФ). к сожалению, процессуальный статус такого лица недостаточно детализирован, что приводит к наделению его правами через систему отсылочных норм, закрепляющих права иных субъектов. Так ч. 1 ст. 437 УПК РФ указывает на принадлежность такому лицу прав, получивших закрепление в ст. 46 и 47 УПК РФ, т.е., принадлежащих подозреваемому и обвиняемому. Таким образом, хотя в УПК РФ и не поставлен знак равенства между обвиняемым, подозреваемым и лицом, в отношении которого ведется производство о применении принудительных мер медицинского характера, вполне обоснованно такое лицо наделяется правами уголовно преследуемого лица, в том числе, и правом на защиту. Этот же вывод следует и из разъяснений данных Верховным Судом РФ в п. 1 Постановления Пленума от 30 июня 2015 г. № 29 «О практике применения судами законодательства, обеспечивающего право на защиту в уголовном судопроизводстве» ${ }^{1}$. В частности, Верховный Суд РФ указал на то, что лицо, в отношении которого ведется или велось производство о применении принудительных мер медицинского характера, наделяется предусмотренным ст. 16 УПК РФ правом на защиту, которое «является одним из принципов уголовного судопроизводства, действовавших во всех его стадиях».

1 О практике применения судами законодательства, обеспечивающего право на защиту в уголовном судопроизводстве : Постановление Пленума Верховного Суда РФ от 30 июня 2015 г. № 29 // СПС «КонсультантПлюс».
Однако согласимся с исследователями, которые указывают, что УПК РФ изначально в недостаточной степени учитывал особенности лиц с психическим расстройствами и предусматривал недостаточный объем гарантий обеспечения их прав [3, с. 29]. Следует признать несовершенной и систему гарантий обеспечения права на защиту таких лиц при решении вопроса в медицинскую организацию, оказывающую психиатрическую помощь в стационарных условиях.

В соответствии с признаваемыми в России международными стандартами по общему правилу психиатрическая помощь может быть им оказана только на добровольной основе. Принудительная госпитализация в психиатрический стационар рассматривается как исключение из данного правила и может применяться только в рамках установленных законом процедур. Одна из таких процедур предусмотрена уголовно-процессуальным законодательством для решения вопроса о способности лица в силу состояния психического здоровья нести уголовную ответственность и для оказания ему принудительной психиатрической помощи по основаниям, связанным с угрозой собственной жизни и здоровью и жизни и здоровью окружающих. Такое принуждение должно носить законный и недискриминационный характер, поскольку «любое психически больное лицо имеет право на осуществление всех гражданских, политических, экономических, социальных и культурных прав» ${ }^{2}$, получивших закрепление в основополагающих международных до-

2 Принципы защиты психически больных лиц и улучшения психиатрической помощи : приняты резолюцией 46/119 Генеральной Acсамблеи от 17 дек. 1991 г. // OOH. URL: https:// www.un.org/ru/documents/decl_conv/conventions/ mental_helth_care.shtml. 
кументах. Таким образом, допускаемое при принудительной госпитализации душевнобольного лица в уголовном судопроизводстве ограничение права лица на свободу и личную неприкосновенность должно быть обоснованным, на что ранее указывалось учеными, изучающими данную проблему [4].

В период производства по уголовному делу лицо, в отношении которого ведется производство о применении принудительных мер медицинского характера, может быть помещено в психиатрический стационар. Российский законодатель предусмотрел такое помещение как для лиц, к которым ранее была применена мера пресечения в виде заключения под стражу, так и для лиц, не содержащихся под стражей. И в том, и в другом случае такое помещение будет носить недобровольный характер и подразумевает ограничение права на свободу и личную неприкосновенность в смысле, определяемом подп. е) п. 1 ст. 5 Европейской конвенции о защите прав человека ${ }^{3}$. При этом в системе уголовного судопроизводства должны быть созданы необходимые процессуальные условия для реализации как права на справедливое судебное разбирательство, так и права на защиту, поскольку «охрана общечеловеческих ценностей в сфере уголовного судопроизводства приобретает особое значение» [5, с. 201].

Принудительное помещение лица в психиатрический стационар при производстве о применении принудительных мер медицинского характера носит условный характер, т.е. может быть реализовано исключительно при наличии соответствующих оснований.

3 Конвенция о защите прав человека и основных свобод : (заключена в г. Риме 4 нояб.1950) : (с изм. от 13 мая 2004) // European Court of Human Rights. URL: https://www.echr.coe.int/Documents/ Convention_RUS.pdf.
В соответствии с ч. 1 ст. 435 УПК РФ, единственным основанием для перевода подозреваемого, обвиняемого в период производства предварительного следствия или дознания в медицинскую организацию, оказывающую психиатрическую помощь, является установление факта психического заболевания у данного лица. Поэтому правовое значение имеет момент установления этого факта. Как отмечают исследователи, разрешение данного вопроса возможно по результатам судебно-психиатрической экспертизы, установившей психическое заболевание, когда лицо нуждается в принудительном лечении в психиатрическом стационаре до выхода из болезненного состояния [6]. Обязательное установление факта психического заболевания указано законодателем в качестве единственного условия для перевода лица из-под стражи в психиатрический стационар. Однако сущность такого помещения и его цели вызывают много вопросов.

В п. 2 ст. 435 УПК РФ есть указание на возможность недобровольного помещения лица в медицинский стационар при соблюдении условий, указанных в ст. 203 УПК РФ. В данном случае основание такого помещения связывается с необходимостью производства судебно-медицинской или судебнопсихиатрической экспертизы и необходимостью ее производства только в стационарных условиях.

Таким образом, целью «промежуточного» помещения лица, в отношении которого ведется производство о применении принудительных мер медицинского характера, в психиатрический стационар может быть или лечение с целью стабилизации психического состояния, или его экспертное обследование. При этом разведение соответствующих оснований по разным частям 
анализируемой статьи УПК РФ не дает ответа на вопрос о возможности комбинирования или принятия каких-либо решений с иной целью, нежели чем указана в соответствующем пункте. Хотя, разрабатывая такую конструкцию, законодатель хотел наилучшим образом обеспечить права лиц с психическими расстройствами, ее практическая реализация далека от оптимальной, затрудняет реализацию лицом права на защиту, не всегда позволяет обеспечить разумные сроки производства по делу. Ведь лицу, переведенному из следственного изолятора в лечебное учреждение соответствующего профиля, требуется не только лечение, но и то самое экспертное обследование по результатам такого лечения. Помещение лица, не содержащегося под стражей, в психиатрический стационар может также быть сопряжено с существенным ухудшением его психического состояния и необходимостью экстренного лечения, но, с целью недопущения здесь злоупотреблений со стороны органов уголовного судопроизводства, предлагается решать этот вопрос за его рамками, что нельзя признать всегда эффективным в плане правовой защиты рассматриваемых лиц.

Полагаем, что существенным недостатком действующего российского уголовно-процессуального закона является отсутствие определенности в понимании характера и правовой природы такой принудительной меры как помещение лица в медицинскую организацию, оказывающую психиатрическую помощь в стационарных условиях. Эта неопределенность породила определенную научную дискуссию о том, имеем ли мы дело: с особой мерой пресечения [7] или с мерой, заменяющей меру пресечения [8], мерой, обеспечивающей проведение стационарной судебно-психиатрической экспертизы [9, с. 1097], или с мерой, позволяющей лицу, в отношении которого, ведется производство о применении принудительных мер медицинского характера, получить доступ к необходимому лечению [10].

Согласимся с тем, что в основном ст. 435 УПК РФ направлена на обеспечение прав психически больных лиц, незамедлительное начало их лечения, не дожидаясь окончания производства по уголовному делу, для чего и требуется перевод в соответствующую медицинскую организацию. Такой подход полностью соответствует и позиции Конституционного Суда РФ, выраженной им в Постановлении 20-П от 24 мая 2018 г., где указано, что соответствующий перевод из СИЗО в психиатрический стационар следует рассматривать как временную принудительную меру. Конституционный Суд РФ обоснованно акцентировал внимание на необходимости обеспечения соответствующих процессуальных гарантий от «злоупотреблений в данной сфере» и соответствующего судебного контроля ${ }^{4}$.

К сожалению, практическая реализация лицом, в отношении которого может быть принято соответствующее решение, его процессуальных прав может быть затруднена именно в связи с его психическим состоянием. Однако и сама процедура принудительного перевода лица, находящегося под стражей, в психиатрическое лечебное учреждение является недостаточно проработанной, что затрудняет практическое применение соответствующих уголовно-процессуальных норм.

4 По делу о проверке конституционности ст. 435 Уголовно-процессуального кодекса Российской Федерации в связи с жалобами граждан Д. и К. : Постановление Конституционного Суда РФ от 24 мая 2018 г. № 20-П // Законы, кодексы, нормативные и судебные акты. URL: https:// legalacts.ru/sud/postanovlenie-konstitutsionnogosuda-rf-ot-24052018-n-20-p/. 
Ряд проблем возникает в связи с отсутствием в ст. 435 УПК РФ срока, на который лицо может быть помещено в психиатрический стационар. Диспозиция нормы, закрепленной в данной статье, также не определяет механизм установления, исчисления, продления, отмены избранной в отношении указанного лица меры пресечения в виде заключение под стражу.

При разрешении вопросов, связанных с принудительным помещением лица в психиатрический стационар в рамках уголовного дела, суды сталкиваются с проблемой определения типа медицинской организации, с установлением сроков перевода в стационар. На ряд вопросов попытался дать ответы Конституционный Суд РФ в упомянутом выше решении, подчеркнув важность соблюдения прав лица, которое принудительно помещается в психиатрический стационар, в том числе и его права на личное участие в рассмотрении судом вопроса о его переводе в медицинскую организацию для оказания психиатрической помощи.

Такая позиция Конституционного Суда РФ полностью соответствует и требованиям международного права, которое рассматривает лиц, в отношении которых рассматривается вопрос о переводе в медицинскую организацию, оказывающую психиатрическую помощь, не в качестве объектов, а в качестве самостоятельных субъектов процесса, наделенных соответствующими правами ${ }^{5}$.

Вполне определенную позицию по данному вопросу высказал и Верховный Суд РФ, указавший на важность обеспечения права лица, в отношении которо-

5 Принципы защиты психически больных лиц и улучшения психиатрической помощи : приняты резолюцией 46/119 Генеральной Ассамблеи от 17 дек. 1991 г. // OOH. URL: https://www. un.org/ru/documents/decl_conv/conventions/mental_helth_care.shtml. го ведется производство о применении принудительных мер медицинского характера, лично участвовать в производстве по делу и самостоятельно реализовывать свои процессуальные права ${ }^{6}$. Однако на практике возможности реализации лицом права на защиту могут быть ограничены по независящим причинам, поскольку болезненное состояние психики может не позволить ему лично отстаивать свою процессуальную позицию и потребует осуществления его защиты иными участниками - защитником и законным представителем. С одной стороны, лицо, имеет право на самозащиту, в том числе и при решении вопроса о применении к нему процессуального принуждения, с другой, - пребывание лица в психическом состоянии, представляющем угрозу его жизни и здоровью, а также окружающим, скорее всего, не позволит ему воспользоваться этим правом.

Что касается вопроса сроков нахождения лица в стационаре и возможности его продления, то соответствующий пробел в законодательстве также удалось закрыть через толкование норм, данное Конституционным Судом РФ, указавшим, что «суд, принимая решение, предусмотренное ч. 1 ст. 435 УПК Российской Федерации, при наличии для этого медицинских показаний, зафиксированных в заключении экспертов, участвующих в производстве судебно-психиатрической экспертизы, и, при необходимости, в медицинском заключении медицинской организации, оказывающей психиатрическую помощь в стационарных условиях, обязан указать срок, на который лицо помеща-

${ }^{6}$ О практике применения судами принудительных мер медицинского характера : Постановление Пленума Верховного Суда РФ от 7 апр. 2011 г. № 6 // Верховный Суд Российской Федерации. URL: https://www.vsrf.ru/documents/own/8236/. 
ется в соответствующую медицинскую организацию, в том числе указать календарную дату его истечения, а продление этого срока должно осуществляться с учетом положений данного Кодекса, определяющих порядок продления срока содержания под стражей» ${ }^{7}$.

Также Конституционный Суд РФ в указанном Постановлении разъяснил, что нахождение лица в медицинском учреждении, оказывающим психиатрическую помощь, допускается только при наличии к этому оснований, по которым он был госпитализирован, а продление такой госпитализации допускается, в порядке ст. 109 УПК РФ, предусматривающей продление срока содержания под стражей. При этом лицо, госпитализированное в медицинскую организацию, в течение первых шести месяцев не реже одного раза в месяц подлежит освидетельствованию комиссией врачей-психиатров для решения вопроса о продлении госпитализации. Полагаем, что такая позиция Конституционного Суда РФ полностью соответствует, так называемым, критериям Винтерверта, зафиксированным в одном из решений Европейского Суда по правам человека ${ }^{8}$, где было установлено, что принудительное помещение лица в психиатрический стационар может быть расценено как его законное задержание и лишение свободы при соблюдении трех условий: 1) установление факта наличия у него психического

7 По делу о проверке конституционности ст. 435 Уголовно-процессуального кодекса Российской Федерации в связи с жалобами граждан Д. и К. : Постановление Конституционного Суда РФ от 24 мая 2018 г. № 20-П // Законы, кодексы, нормативные и судебные акты. URL: https:// legalacts.ru/sud/postanovlenie-konstitutsionnogosuda-rf-ot-24052018-n-20-p/.

${ }^{8}$ Винтерверп (Winterwerp) против Нидерландов (жалоба № 6301/73) : Постановление ЕСПЧ от 24 окт. 1979 г. // СПС «КонсультантПлюс». расстройства, на основе объективных медицинских доказательств; 2) характер и степень такого расстройства должны оправдывать лишение свободы; 3) обоснованность длительности нахождения лица в таком стационаре должна соотноситься с сохранением расстройства.

Принятие Конституционным Судом РФ анализируемого выше Постановления от 24 мая 2018 г. позволило в определенной мере уточнить механизм исчисления, продления, отмены избранной меры пресечения в виде заключение под стражу в отношении подозреваемого, обвиняемого, помещенного в медицинскую организацию, оказывающую психиатрическую помощь в стационарных условиях.

Судам стало легче определять условия помещения таких лиц в указанные медицинские организации, что снизило риск нарушение прав, свобод и законных интересов участников уголовного судопроизводства, которыми не перестают являться лица, помещенные в психиатрический стационар в порядке, предусмотренном ст. 435 УПК РФ. Однако решение КС РФ можно считать только первым шагом на пути установления дополнительных процессуальных гарантий прав душевнобольных лиц. Еще одним важным шагом является внесение Правительством Российской Федерации в марте 2021 г. в Государственную Думу Российской Федерации законопроекта, предусматривающего внесение существенных изменений в ст. 435 УПК РФ ${ }^{9}$. Однако предлагаемые изменения вызывают ряд вопросов, так

9 О внесении изменений в Уголовно-процессуальный кодекс Российской Федерации в части установления срока, на который лицо, содержащееся под стражей, временно помещается в медицинскую организацию, оказывающую психиатрическую помощь в стационарных условиях : законопроект № 1132362-7 // Система обеспечения законодательной деятельности. URL: https://sozd.duma.gov.ru/bill/1132362-7\#bh_hron. 
как их реализация приведет к фактическому отнесению перевода лица в медицинскую организацию, оказывающую психиатрическую помощь в стационарных условиях, к мерам пресечения, причем носящим комбинированный характер. Однако при этом сама система мер пресечения не претерпевает необходимых изменений. Очевидно, что практическая реализация данной правительственной инициативы вызовет в правоприменительной практике новые вопросы.

Полагаем, что необходимо продолжить научное исследование дан- ных вопросов, которые могут носить и межотраслевой характер. На уровне совершенствования уголовно-процессуального закона представляется необходимым закрепление в разделе IV УПК РФ специальной принудительной меры - помещение лица в медицинскую организацию, оказывающую психиатрическую помощь в стационарных условиях, с обязательным уточнением прав такого лица и установлением соответствующих гарантий реализации им этих прав, в том числе, и права на защиту.

\section{СПИСОК ИСТОЧНИКОВ}

1. Смирнова И.Г. К вопросу о законодательном регулировании передачи лиц, страдающих психическими расстройствами, для проведения принудительного лечения / И.Г. Смирнова, В.И. Аксентьев // Global and Regional Research. - 2020. - Т. 2, № 1. - С. 568-572.

2. Неретин Н.Н. К вопросу о праве обвиняемого на защиту в уголовном судопроизводстве России / Н.Н. Неретин // Вестник Оренбургского государственного университета. 2009. - № 3 (97). - С. 93-95.

3. Марковичева Е.В. Обеспечение права на справедливое судебное разбирательство в производстве о применении принудительных мер медицинского характера / Е.В. Марковичева // Судебная власть и уголовный процесс. - 2019. - № 4. - С. 28-31.

4. Мищенко Е.В. Международно-правовое закрепление особенностей правового статуса лиц, к которым могут быть применены принудительные меры медицинского характеpa / Е.В. Мищенко // Вестник Оренбургского государственного университета. — 2011. № 3. - С. 101-105.

5. Смирнова И.Г. Борьба с преступностью и уголовное судопроизводство / И.Г. Смирнова // Криминологический журнал Байкальского государственного университета экономики и права. - 2014. - № 3. - С. 200-205.

6. Шишков С.Н. Помещение в психиатрический стационар / С.Н. Шишков // Законность. - 2003. - № 11. - С. 32-37.

7. Лавдаренко Л.И. К вопросу о правах лица, подвергаемого принудительному помещению в психиатрический стационар в уголовном судопроизводстве / Л.И. Лавдаренко // Российский следователь. - 2010. - № 18. - С. 8-11.

8. Суховерхова Е.В. Помещение в психиатрический стационар в соответствии со ст. 435 УПК РФ - разновидность заключения под стражу или отдельная мера пресечения? / Е.В. Суховерхова // Вестник Московского университета МВД России. — 2012. № 3. - C. $80-82$.

9. Научно-практический комментарий к Уголовно-процессуальному кодексу Российской Федерации / под ред. В.М. Лебедева, В.П. Божьева. - 6-е изд., доп. и перераб. - Москва : Юрайт, 2010. — 1209 с.

10. Кудрявцева А.В. Правовая природа и практика применения процессуальной меры, предусмотренной ст. 435 УПК РФ / А.В. Кудрявцева // Уголовное право. — 2014. — № 6. C. $95-100$.

\section{REFERENCES}

1. Smirnova I.G., Aksentev V.I. To the Question of Legislative Regulation of Transfer of Persons Affecting Mental Disorders for Care of Forced Treatment. Global and Regional Research, 2020, vol. 2, no. 1, pp. 568-572. (In Russian). 
2. Neretin N.N. To the question of the right of the accused to defense in Russian criminal court proceedings. Vestnik Orenburgskogo gosudarstvennogo universiteta $=$ Vestnik of the Orenburg State University, 2009, no. 3, pp. 93-95. (In Russian).

3. Markovicheva E.V. Securing the Right to a Fair Trial in a Procedure Regarding the Application of Compulsory Medical Measures. Sudebnaya vlast' $i$ ugolovnyi protsess $=$ Judicial Authority and Criminal Process, 2019, no. 4, pp. 28-31. (In Russian).

4. Mishchenko E.V. The International Legal Consolidation of Special Features of Legal Status of Persons, to which the Forced Measures of Medical Nature can be Applied. Vestnik Orenburgskogo gosudarstvennogo universiteta $=$ Vestnik of the Orenburg State University, 2011, no. 3, pp. 101-105. (In Russian).

5. Smirnova I.G. Crime Fighting and Criminal Proceedings. Kriminologicheskii zhurnal Baikal'skogo gosudarstvennogo universiteta ekonomiki i prava = Criminology Journal of Baikal National University of Economics and Law, 2014, no. 3, pp. 200-205. (In Russian).

6. Shishkov S.N. Placement into a Psychiatric Clinic. Zakonnost ${ }^{\prime}=$ Legality, 2003, no. 11, pp. 32-37. (In Russian).

7. Lavdarenko L.I. To the question of the rights of a person under compulsory treatment in a mental health institution in criminal court proceedings. Rossiiskii sledovatel' $=$ Russian Investigator, 2010, no. 18, pp. 8-11. (In Russian).

8. Sukhoverkhova E.V. Placement in a Psychiatric Hospital in Accordance with Art. 435 the Criminal Procedure Code of the Russian Federation - a kind of Imprisonment or a Single Measure of Restraint? Vestnik Moskovskogo universiteta MVD Rossii = Bulletin of Moscow University of the Ministry of Internal Affairs of Russia, 2012, no. 3, pp. 80-82. (In Russian).

9. Lebedev V.M., Bozhev V.P. (eds). Scientific Comments to the Criminal Procedure Code of the Russian Federation. $6^{\text {th }}$ ed. Moscow, Yurait Publ., 2010. 1209 p.

10. Kudryavtseva A.V. The Legal Nature and Practice of Application of a Procedural Measure Envisaged by Article 435 of the Code of Criminal Procedure of the Russian Federation. Ugolovnoe pravo $=$ Criminal Law, 2014, no. 6, pp. 95-100. (In Russian).

\section{ИНФОРМАЦИЯ ОБ АВТОРЕ}

Шатрова Анна Вячеславовна - аспирант кафедры уголовно-процессуального права им. Н.В. Радутной Российского государственного университета правосудия, г. Москва, Российская Федерация; судья Норильского городского суда Красноярского края, г. Норильск, Российская Федерация.

\section{INFORMATION ABOUT THE AUTHOR}

Anna V. Shatrova - Ph.D. Student, Department of Criminal Procedure Law named after N.V. Radutnaya, Russian State University of Justice, Moscow, the Russian Federation; Judge, Norilsk City Court of Krasnoyarsk Krai, Norilsk, the Russian Federation.

Поступила в редакцию / Received 30.04.2021

Одобрена после рецензирования / Approved after reviewing 25.05.2021

Принята к публикации / Accepted 16.08.2021

Дата онлайн-размещения / Available online 03.09.2021 